\title{
Amygdalus orientalis (Mill) ve Amygdalus turcomanica (Lincz) badem türlerinin bazı pomolojik ve morfolojik özelliklerinin saptanması
}

Determination of some morphological and pomological characteristics of Amygdalus orientalis (Mill) and Amygdalus turcomanica (Lincz) almond species

\author{
Safder BAYAZIT ${ }^{1}$ (D) , Oğuzhan ÇALIŞKAN ${ }^{1}$
}

${ }^{1}$ Hatay Mustafa Kemal Üniversitesi, Ziraat Fakültesi, Bahçe Bitkileri Bölümü, Antakya, Hatay.

MAKALE BILGISI / ARTICLE INFO

\section{Makale tarihçesi / Article history:}

DOI: $10.37908 /$ mkutbd.940588

Geliş tarihi /Received:21.05.2021

Kabul tarihi/Accepted:06.07.2021

\section{Keywords:}

Wild almond, Amygdalus orientalis, Amygdalus turcomanica, morphology, pomology.

Corresponding author: Safder BAYAZIT

$\varangle$ : sbayazit@mku.edu.tr

\section{ÖZET / ABSTRACT}

Aims: In the study carried out, the pomological and morphological characteristics of 13 genotypes belonging to Amygdalus orientalis (Mill) species and 8 genotypes belonging to Amygdalus turcomanica (Lincz) species selected in Gaziantep were tried to be determined.

Methods and Results: In the study, shelled fruit weight (g), shelled fruit dimensions (length, width, height) $(\mathrm{mm})$, shell thickness $(\mathrm{mm})$, the kernel weight $(\mathrm{g})$, double kernel rate $(\%)$, leaf length $(\mathrm{cm})$, leaf width $(\mathrm{cm})$, leaf color, and leaf area $\left(\mathrm{cm}^{2}\right)$ were determined. As a result of the study, the average shelled and kernel weight, width, height and height values of Amygdalus orientalis (Mil) genotypes were higher than Amygdalus turcomanica (LinCz) genotypes in both years of the study. Nut weight varied between $0.38 \mathrm{~g}$ and $0.99 \mathrm{~g}$ in Amygdalus orientalis (Mill) genotypes, while it varied between $0.41 \mathrm{~g}$ and $0.95 \mathrm{~g}$ in Amygdalus turcomanica (Lincz) genotypes. Fruits were longer in Amygdalus orientalis (Mill) genotypes compared to Amygdalus turcomanica (Lincz) genotypes, and larger and thicker in Amygdalus turcomanica (Lincz) genotypes, and the shell thickness of this species was higher. The kernel properties were also performed in parallel with the shelled features. It was determined that Amygdalus turcomanica (Lincz) genotypes had more stems, dense crowned, more thorny, green leaves and smaller sizes compared to Amygdalus orientalis (Mill) genotypes.

Conclusions: It has been determined that tree size, stem number, leaf colors and fruit characteristics can be used in species identification. Considering the size of the tree, it was concluded that it can be considered as a dwarf rootstock, and it is necessary to determine the compatibility and rootstock capability for other stone fruit species, especially almonds. Significance and Impact of the Study: Wild almond species are important genetic resources due to their resistance to adverse climatic and soil conditions and the possibility of being used as dwarf rootstock for Prunus species. In order for genetic resources to be used in breeding and production, all their characteristics should be determined. In this study, determining the pomological and morphological characteristics of two almond species that grow naturally in the flora of Turkey is the basis for breeding and breeding studies.

Atıf / Citation: Bayazıt S, Çalışkan O (2021) Amygdalus orientalis (Mill) ve Amygdalus turcomanica (Lincz) badem türlerinin bazı pomolojik ve morfolojik özelliklerinin saptanması MKU. Tar. Bil. Derg. 26(3) : 543-553. DOI: 10.37908/mkutbd.940588 


\section{Giriş}

Bitkilerin ilk olarak ortaya çıktığı ve evrimlerini tamamladıkları yerlere "Gen Merkezi" veya "Anavatan" adı verilmektedir. Türkiye, Dünya üzerinde tespit edilen 8 gen merkezinden Akdeniz ve Yakın Doğu gen merkezleri içerisinde yer alması nedeniyle ayrı bir öneme sahiptir (Demir, 1990; Ağaoğlu ve ark., 1995) ve birçok kültür bitkisinin anavatanı konumundadır. Türkiye'nin ekolojik koşullarının bahçe bitkilerinin yetiştiriciliğine uygun olması, göç yollarının üzerinde bulunması ve tarihin ilk çağlarından beri pek çok medeniyetin yaşadığı bir alan olması çok sayıda tür ve çeşit zenginliğine sahip olmasının en önemli nedenleridir (Demir, 1990; Ağaoğlu ve ark., 1995). Çok zengin gen kaynaklarına sahip olan ülkemiz pek çok bitki türünün olduğu gibi bademin de anavatanıdır. Badem (Prunus dulcis (Miller) D.A. Webb), Rosales takımının, Rosaceae familyasının Prunoideae alt familyasının Amygdalus cinsine girer (Özbek, 1978). Bu cins içerisinde $30^{\prime}$ dan fazla badem türünün olduğu bilinmektedir. Bu türlerden $A$. orientalis (Mill), $A$. turcomanica (Lincz), A. fenzliana (Fritch), $A$. trichamgdalus (Hand-Mazz) Woronov, A. arabica (Oliver) ve $A$. webbi (Spach) türleri ülkemiz florasında yer almaktadır. Bu türlerden $A$. turcomanica Güneydoğu Anadolu Bölgesi'nde çok yoğun olarak yetişirken, $A$. orientalis Güneydoğu Anadolu ve Orta Anadolu Bölgelerinde yetişmektedir (Kester ve Asay, 1975; Bayazıt, 2007). A. orientalis Mill. 1-2(3) m boylanabilen, çalı formunda bitkiler oluşturmaktadır. Yaprakları sık tüylü, meyveler küçük, sert kabuklu ve sert kabuk yüzeylerinde oluklar bulunmaktadır (Browicz ve Zielinski, 1984; Denisov, 1988; Kester ve ark., 1990; Browicz ve Zohary, 1996, Bayazıt, 2007). Küçük ve küre biçiminde meyvelere sahip olan $A$. turcomanica (Lincz) türüne ait bitkiler çalı formunda, çok gövdelidir, ülkemizin Gaziantep ve Şanlıurfa illerinde yayılım göstermiştir (Kester ve ark., 1991; Browicz ve Zohary, 1996; Bayazit, 2007). Ülkemiz orijinli badem türleri kurak alanların erozyona karşı korunmasında etkili oldukları gibi kültür bademine anaç olarak ta kullanılabilmektedirler. Taç yapılarının kültür bademlerine göre çok küçük olması nedeniyle bodur anaç olarak kullanılması muhtemeldir. Nitekim Bayazıt (2007), Orta Anadolu ve Güneydoğu Anadolu bölgelerinde $A$. orientalis türüne ait doğal olarak yetişen bitkilerde taç yüksekliğinin $151 \mathrm{~cm}$ ile 238 $\mathrm{cm}$ arasında değiştiğini belirtmiştir. Atlı (2008), A. orientalis badem türüne ait genotiplerin kültür badem çeşitleri ile uyuşmada bir probleminin olmadığını, bodur özelliği nedeniyle Gaziantep ili ekolojik koşullarında Texas çeşidi üzerine aşılı 4 yaşlı Nonpareil çeşidinden dekara verim $83.8 \mathrm{~kg} \mathrm{da}^{-1}$ iken, $A$. orientalis üzerine aşılı
Nonpareil çeşidinden ise $351.1 \mathrm{~kg} \mathrm{da}{ }^{-1}$ olduğunu bildirmektedir.

Yabani badem türlerinin kültür bademleri için gerçekleştirilen ıslah çalışmalarında geç çiçeklenme, kendine verimlilik, kurak, kireçli ve tuzlu toprak koşullarına dayanıklılık gibi özelliklerinden de faydalanılmaktadır (Denisov, 1988). Bu nedenlerden dolayı bu türlerin pomolojik, morfolojik, fenolojik ve moleküler tanımlamalarına ilişkin birçok araştırma gerçekleştirilmiştir (Martinez-Gómez ve ark., 2005; Bayazit, 2018).

Gıda güvenliği açısından içinde bulunduğumuz yüzyılın en önemli doğal kaynağının genetik kaynaklar olduğu kabul edilmektedir. Bu kaynaklara sahip çıkmak, genetik materyalleri muhafaza etmekle birlikte bu kaynakların faydaya dönüştürülmesini, ıslah ve üretimde faydalanılabilecek özelliklerinin belirlenmesini zorunlu kılmaktadır.

Yabani ve ilkel populasyonlar modern kültür çeşitlerinin fakir olan gen havuzlarının genişletilmesinde de kullanılmaktadır (Şehirali ve ark., 2005). Günümüzde üstün verimli, fakat dar genetik tabanlı olan modern çeşitler başta çevresel baskılara (hastalık, zararlı, soğuk ve kurak vb.) dayanıklılık yönünden gen eksikli olduklarından, ıslahçılar sürekli olarak kalıtsal materyalin yeni kaynaklarını aramaktadırlar. Sürdürülebilir kullanım, bitki genetik kaynaklarının iyi değerlendirilmesine bağlıdır. Bitki genetik kaynaklarının gıda ve tarım için kullanımını iyileştirmek, materyalin korunma süresince tüm özelliklerinin belirlenmesiyle sağlanabilir.

$\mathrm{Bu}$ hedeflerden yola çıkılarak gerçekleştirilen bu araştırmanın amacını da kültür bademine anaç olarak kullanılabilmesi nedeniyle $A$. orientalis (Mill) ve $A$. turcomanica (Lincz) badem türlerine ait genotiplerde pomolojik ve morfolojik özelliklerinin saptanması oluşturmuştur.

\section{MATERYAL ve YÖNTEM}

Bu araştırma 2014 ve 2015 yıllarında gerçekleştirilmiştir. Araştırmada, Gaziantep ilinden seçilen A. orientalis (Mill) türüne ait 13 genotip, $A$. turcomanica (Lincz) türüne ait 8 genotip materyal olarak kullanılmıştır. Gerek morfolojik gerekse pomolojik özelliklerinin kıyaslanması amacıyla da Texas badem çeşidi kontrol olarak kullanılmıştır.

Pomolojik özellikler badem türlerine ait her genotipte 3 yinelemeli ve her yinelemede 10 adet meyve olacak şekilde alınan toplam 30 adet kabuklu ve iç bademde Bayazıt (2007)'a göre gerçekleştirilmiştir. Kabuklu ve iç badem özelliklerinden ortalama kabuklu ve iç badem ağırlığı (g) kabuklu ve iç badem boyutları (en, boy, 
yükseklik) (mm), kabuk kalınlığı ( $\mathrm{mm})$, çift iç oranı (\%) ve iç badem oranı (\%) belirlenmiştir. Kabuklu badem şekil indeksi (en/boy) meyve eninin meyve boyuna bölünmesiyle verilen formül kullanılarak belirlenmiştir.

$$
\text { Kabuklu badem şekil indeksi }=\frac{\text { Ortalama Genişlik }(\mathrm{mm})}{\text { Ortalama Boy }(\mathrm{mm})} \times 100
$$

Kabuklu badem şekil indeksi <40 'çok dar'; 40-48 'dar'; 49-55 'orta'; 56-65 'geniş' ve >65 'çok geniş' olarak değerlendirilmiştir. İç badem genişlik indeksi verilen formül kullanılarak hesaplanmıştır;

$$
\text { Genişlik İndisi }=\frac{\text { Ortalama Genişlik }(\mathrm{mm})}{\text { Ortalama Boy }(\mathrm{mm})} \times 100
$$

Genişlik indisi 50'den küçük olanlar 'dar', 50-60 arası 'geniş̧̧e' ve 60 'dan büyük olanlar ise 'geniş' olarak sınıflandırımıştır. iç badem kalınlık indeksi verilen formül kullanılarak hesaplanmıştır.

$$
\text { Kalınlık İndisi }=\frac{\text { Ortalama Kalınlık }(\mathrm{mm})}{\text { Ortalama Boy }(\mathrm{mm})} \times 100
$$

Kalınlık indisi 30'dan küçük ise 'yassı', 30-38 arası ise 'kalınca' ve 38 'den büyük ise 'kalın' olarak değerlendirilmiştir.

Morfolojik özelliklerden gövde sayısı (adet) her genotip için sayılarak elde edilmiştir. Dikenlilik durumu (dikenli, değil), taç gelişimi (bodur, çok bodur) ve yaprak rengi gözlemsel olarak belirlenmiştir. Badem genotiplerinde yaprak uzunluğu $(\mathrm{mm})$ ve genişliği $(\mathrm{mm})$ cetvel ile ve yaprak alanı $\left(\mathrm{cm}^{2}\right)$ alan ölçüm aletinde (Li 3100 area meter) ölçülerek belirlenmiştir. Ölçümleri yaprakların normal iriliklerine ulaştıkları 15 Temmuz'da 3 yinelemeli ve her yinelemede 10 adet yaprak olacak şekilde tesadüfen alınan 30 adet olgun yaprakta gerçekleştirilmiştir.

\section{BULGULAR ve TARTIŞMA}

Denemede yer alan yabani badem türlerine ait genotiplerin kabuklu badem özelliklerine ilişkin ölçüm sonuçları Çizelge 1'de verilmiştir. Çizelgeden de görüleceği gibi ortalama kabuklu badem ağırlığı, boyu ve kabuk kalınlığı değerleri yıllara göre değişiklik göstermemiştir. Bununla birlikte, denemede yer alan badem türlerine ait genotiplerde kabuklu badem özelliklerine ilişkin değerlerin ortalamaları arasındaki farklar istatistiki olarak önemli olmuştur.

En yüksek kabuklu badem ağırlığı beklenildiği şekilde $3.48 \mathrm{~g}$ ile Texas badem çeşidinden elde edilmiştir. $A$. orientalis badem türüne ait genotiplerin kabuklu badem ağırlıkları 0.38 g (O5) ile 0.99 g (013) arasında değişmiştir. $A$. turcomanica türüne ait genotipler içerisinde ise en düşük kabuklu badem ağırlığı $0.41 \mathrm{~g}$ ile
T5 genotipinde elde edilirken, en yüksek değer ise $0.95 \mathrm{~g}$ ile T2 genotipinden elde edilmiştir. Öteki badem genotiplerinin kabuklu badem ağırlıkları verilen değerler arasında dağılım göstermiştir.

En yüksek kabuklu badem eni, boyu ve yüksekliği değerleri ortalama kabuklu badem ağırlığında olduğu şekilde denemede kontrol olarak kullanılan Texas badem çeşidinden elde edilmiştir. $A$. orientalis genotiplerine ait kabuklu bademlerde meyve eni değerleri $(9.43 \mathrm{~mm}) A$. turcomanica badem türüne ait genotiplerden elde edilen değerlerden $(10.41 \mathrm{~mm})$ daha düşük olmuştur. Buna karşılık $A$. orientalis genotiplerinde kabuklu bademlerin uzunluk ortalamaları $(17.13 \mathrm{~mm}), \quad A$. turcomanica genotiplerinden (13.39 $\mathrm{mm})$ yüksek olmuştur. Denemede yer alan badem türlerinde ise kabuklu badem kalınlıkları ( $8.09 \mathrm{~mm}$ ve $8.50 \mathrm{~mm}$ ) yakın olmuştur.

Kabuk kalınlığı değerleri yıllara göre farklılık göstermemiş, badem tür ve genotiplerine göre değişmiştir. A. orientalis genotiplerinde kabuk kalınlıkları $0.49 \mathrm{~mm}$ (011) ile $1.20 \mathrm{~mm}$ (012) arasında değişmiş, genotiplerin ortalaması ise $0.82 \mathrm{~mm}$ olarak elde edilmiştir. A. turcomanica genotiplerinde ise kabuk kalınlığı $0.78 \mathrm{~mm}$ (T4) ile $1.15 \mathrm{~mm}$ (T2) arasında değişmiş, genotiplerin ortalaması ise $0.98 \mathrm{~mm}$ olmuştur.

Gerçekleştirilen ölçümler ve gözlemler neticesinde gerek $A$. orientalis, gerekse $A$. turcomanica badem türlerinde meyve iriliklerinin kültür bademlerine kıyasla çok düşük olduğu görülmüştür. Benzer şekilde kabuk kalınlığı değerleri de düşük gerçekleşmiştir. Yabani badem türlerinde kabuk kalınlığının düşük olmasına karşılık daha sert olduğu da dikkat çekmiştir.

Denemede yer alan badem türleri ile gerçekleştirilen 
önceki araştırmalarda da benzer sonuçlar elde edilmiştir. Nitekim, Shalaby ve ark. (1997), A. orientalis genotiplerınde kabuklu meyve uzunluklarının $1.5 \mathrm{~cm}$ ile $2.5 \mathrm{~cm}$, kabuklu meyve genişliklerinin 1.0 ile $1.5 \mathrm{~cm}$ arasında değiştiğini bildirmiştir. Elde etmiş olduğumuz değerlerin belirtilen değerlerden düşük olduğu görülmektedir. Bununla birlikte Ak ve ark. (1998), 63 AO 01 no'lu $A$. orientalis Mill. tipine ait meyve uzunluğunu $14.31 \mathrm{~mm}$, meyve genişliğini $8.07 \mathrm{~mm}$ olarak belirtmiştir. Bu değerlerin elde etmiş olduğumuz değerlerden düşük ve meyve yüksekliği değerinin $(1.17 \mathrm{~mm})$ ise yüksek olduğu dikkat çekmiştir. Tholkouk ve ark.(2000) Lübnan'da 6 farklı noktadan seçtiği $A$. orientalis genotiplerinde ortalama kabuklu badem ağırlığının $0.5 \mathrm{~g}$ ile $2.1 \mathrm{~g}$, meyve eninin $9.3 \mathrm{~mm}$ ile $16.9 \mathrm{~mm}$, meyve boyunun $14.5 \mathrm{~mm}$ ile $23.2 \mathrm{~mm}$ arasında değiştiğini, ortalama kabuk kalınlığı değerinin ise $0.9 \mathrm{~mm}$ olduğunu belirtmişlerdir. Sorkheh ve ark. (2009) İran'da 5 farklı noktadan seçtikleri $A$. orientalis genotiplerinde ortalama meyve ağırlıklarının $0.4 \mathrm{~g}$ ile $2.1 \mathrm{~g}$ arasında değerler aldığını; kabuklu badem genişliği, uzunluğu ve kabuk kalınlığı değerlerinin ise sırasıyla $10.4 \mathrm{~mm}, 16.2 \mathrm{~mm}$ ve $0.7 \mathrm{~mm}$ olduğunu bildirmişlerdir. Bayazıt (2007) Gaziantep ili $A$. orientalis popülasyonunda ortalama kabuklu badem ağırlığı, genişliği, uzunluğu, kalınlığı ve kabuk kalınlığı değerlerini sırasıyla $0.46 \mathrm{~g}, 8.70 \mathrm{~mm}$, $17.10 \mathrm{~mm}, 7.48 \mathrm{~mm}$ ve $0.79 \mathrm{~mm}$ olarak belirtirken, Orta Anadolu bölgesi $A$. orientalis popülasyonunda $0.85 \mathrm{~g}$, $11.54 \mathrm{~mm}, 21.74 \mathrm{~mm}, 8.04 \mathrm{~mm}$ ve $1.17 \mathrm{~mm}$ olarak belirtmiştir. Araştırıcı aynı çalışmada Gaziantep ili $A$. turcomanica popülasyonunda ortalama kabuklu badem ağırlı̆ıı, genişliği, uzunluğu, kalınlığı ve kabuk kalınlığı değerlerini sırasıyla $0.46 \mathrm{~g}, 9.18 \mathrm{~mm}, 13.43 \mathrm{~mm}, 7.80 \mathrm{~mm}$ ve $1 \mathrm{~mm}$ olarak belirtilmiştir. Atlı (2008) üzerinde çalıştığı A. orienalis genotiplerinde meyve ağılı̆ının $0.42 \mathrm{~g}$ ile $1.90 \mathrm{~g}$, meyve eninin $6.8 \mathrm{~mm}$ ile $12.5 \mathrm{~mm}$, meyve uzunlunun $13.3 \mathrm{~mm}$ ile $20.6 \mathrm{~mm}$ ve meyve yüksekliğinin $7.9 \mathrm{~mm}$ ile $15.7 \mathrm{~mm}$ arasında değiştiğini bildirmiştir. Benzer şekilde Chalak ve ark. (2014) Lübnan'da 7 farklı noktadan elde ettikleri $A$. orientalis genotiplerinde ortalama meyve ağırlığının $0.44 \mathrm{~g}$ ile $1.6 \mathrm{~g}$ arasında değişim gösterdiğini bildirmişlerdir. Bayazit (2018) Gaziantep ilinden seçmiş olduğu $A$. orientalis ve $A$. turcomanica genotiplerinde ortalama meyve ağırlıklarının ve meyve ebatlarının kontrol olarak kullanılan Tuono ve Ferragnes badem çeşitlerine kıyasla çok düşük olduğunu belirtmiştir. Araştırıcı $A$. orientalis genotiplerinde meyve ağılığının $0.25 \mathrm{~g}$ ile $2.30 \mathrm{~g}$ arasında değiştiğini ve ortalama meyve ağılığının $(0.75$ g) A. turcomanica türüne ait genotiplerden elde edilen ortalama ağırlıktan (0.42 g) yüksek olduğunu bildirmiştir. Araştırmada $A$. orientalis genotiplerinde kabuklu badem eni $6.57 \mathrm{~mm}$ ile $16.69 \mathrm{~mm}$, boyu $14.90 \mathrm{~mm}$ ile $27.28 \mathrm{~mm}$ ve meyve kalınlığı $5.85 \mathrm{~mm}$ ile $12.86 \mathrm{~mm}$ arasında değişirken bu değerler $A$. turcomanica türüne ait genotiplerde $8.46 \mathrm{~mm}$ ile $10.18 \mathrm{~mm}, 11.93 \mathrm{~mm}$ ile 14.93 $\mathrm{mm}$ ve $6.97 \mathrm{~mm}$ ile $8.31 \mathrm{~mm}$ arasında değişmiştir. Kabuk kalınlığının 2 badem türünde de yakın olduğunu belirten araştırıcı bu değerin $A$. orientalis genotiplerinde $0.69 \mathrm{~mm}$ ile $2.05 \mathrm{~mm}, A$. turcomanica genotiplerinde $1.05 \mathrm{~mm}$ ile $1.29 \mathrm{~mm}$ arasında değiştiğini bildirmiştir.

iki yıl süreyle gerçekleştirmiş olduğumuz bu araştırmadan elde edilen sonuçlar ile aynı badem türleri kullanılarak gerçekleştirilmiş araştırmaların sonuçları benzerlik göstermekle birlikte farklılıklarda bulunmaktadır. $\mathrm{Bu}$ farklııklar bitkilerin yetiştikleri ekolojilerin farklı olması, bitkilerin bulundukları toprak yapısı, meyve yükü, ağaç yaşı gibi faktörlerden etkilenmektedir. Bununla birlikte meyve özelliklerindeki temel farklılık denemede yer alan badem türlerine ait genotiplerin doğal popülasyonda tohumla çoğalıyor olması nedeniyle genetik açılımdır.

Çizelge 1. Kabuklu badem özellikleri

Table 1. Nut properties

\begin{tabular}{lccccc}
\hline Genotip & Meyve ağırlığı (g) & Meyve eni $(\mathrm{mm})$ & Meyve boyu $(\mathrm{mm})$ & Meyve yüksekliği $(\mathrm{mm})$ & Kabuk kalınlığı $(\mathrm{mm})$ \\
\hline O1 & $0.43 \mathrm{hj}$ & $8.82 \mathrm{~m}$ & $14.88 \mathrm{gl}$ & $7.47 \mathrm{ij}$ & $0.74 \mathrm{gh}$ \\
O2 & $0.39 \mathrm{j}$ & $7.81 \mathrm{n}$ & $15.91 \mathrm{fh}$ & $7.18 \mathrm{j}$ & $0.69 \mathrm{gh}$ \\
O3 & $0.57 \mathrm{e}$ & $9.14 \mathrm{jm}$ & $17.51 \mathrm{de}$ & $7.82 \mathrm{gl}$ & $0.89 \mathrm{df}$ \\
O4 & $0.70 \mathrm{~d}$ & $9.81 \mathrm{fl}$ & $17.13 \mathrm{df}$ & $8.57 \mathrm{e}$ & $0.92 \mathrm{de}$ \\
O5 & $0.38 \mathrm{j}$ & $8.78 \mathrm{~m}$ & $14.76 \mathrm{hı}$ & $7.61 \mathrm{ij}$ & $0.67 \mathrm{~h}$ \\
O8 & $0.53 \mathrm{eg}$ & $9.15 \mathrm{jm}$ & $16.71 \mathrm{ef}$ & $7.70 \mathrm{hI}$ & $0.74 \mathrm{gh}$ \\
O10 & $0.51 \mathrm{eh}$ & $9.09 \mathrm{Im}$ & $16.68 \mathrm{ef}$ & $7.62 \mathrm{I}$ & $0.77 \mathrm{gh}$ \\
O11 & $0.50 \mathrm{fl}$ & $9.11 \mathrm{~km}$ & $17.30 \mathrm{de}$ & $8.36 \mathrm{ef}$ & $0.49 \mathrm{I}$ \\
O12 & $0.60 \mathrm{e}$ & $9.65 \mathrm{gk}$ & $18.20 \mathrm{~d}$ & $8.07 \mathrm{fh}$ & $1.20 \mathrm{~b}$ \\
O13 & $0.99 \mathrm{~b}$ & $11.58 \mathrm{c}$ & $21.30 \mathrm{~b}$ & $9.05 \mathrm{~cd}$ & $0.94 \mathrm{~d}$ \\
O14 & $0.53 \mathrm{~g}$ & $9.43 \mathrm{ol}$ & $16.56 \mathrm{ef}$ & $8.42 \mathrm{ef}$ & $0.80 \mathrm{eg}$ \\
O15 & $0.80 \mathrm{c}$ & $10.71 \mathrm{~d}$ & $19.72 \mathrm{c}$ & $9.47 \mathrm{bc}$ & $0.97 \mathrm{~cd}$ \\
\hline
\end{tabular}


Çizelge 1 (devamı). Kabuklu badem özellikleri

Table 1 (continued). Nut properties

\begin{tabular}{lccccc}
\hline O16 & $0.54 \mathrm{e}$ & $9.46 \mathrm{hl}$ & $16.08 \mathrm{fg}$ & $7.88 \mathrm{gl}$ & $0.75 \mathrm{gh}$ \\
\hline Ortalama & $\mathbf{0 . 5 7}$ & $\mathbf{9 . 4 3}$ & $\mathbf{1 7 . 1 3}$ & $\mathbf{8 . 0 9}$ & $\mathbf{0 . 8 2}$ \\
\hline T1 & $0.51 \mathrm{eh}$ & $10.05 \mathrm{eg}$ & $13.67 \mathrm{I}$ & $8.62 \mathrm{ed}$ & $1.09 \mathrm{cb}$ \\
T2 & $0.95 \mathrm{~b}$ & $13.49 \mathrm{~b}$ & $17.01 \mathrm{df}$ & $9.50 \mathrm{~b}$ & $1.15 \mathrm{~b}$ \\
T3 & $0.50 \mathrm{fl}$ & $10.28 \mathrm{df}$ & $13.93 \mathrm{I}$ & $8.56 \mathrm{e}$ & $0.97 \mathrm{~cd}$ \\
T4 & $0.43 \mathrm{hj}$ & $10.23 \mathrm{df}$ & $10.59 \mathrm{j}$ & $8.64 \mathrm{ed}$ & $0.78 \mathrm{fh}$ \\
T5 & $0.41 \mathrm{j}$ & $9.99 \mathrm{eh}$ & $11.66 \mathrm{j}$ & $7.85 \mathrm{gl}$ & $0.92 \mathrm{de}$ \\
T6 & $0.51 \mathrm{eh}$ & $9.02 \mathrm{Im}$ & $14.81 \mathrm{hl}$ & $8.23 \mathrm{eg}$ & $0.81 \mathrm{eg}$ \\
T7 & $0.44 \mathrm{gj}$ & $9.66 \mathrm{gj}$ & $11.74 \mathrm{j}$ & $8.08 \mathrm{fh}$ & $0.95 \mathrm{~d}$ \\
T8 & $0.58 \mathrm{ef}$ & $10.54 \mathrm{ed}$ & $13.69 \mathrm{I}$ & $8.55 \mathrm{e}$ & $1.13 \mathrm{~b}$ \\
\hline Ortalama & $\mathbf{0 . 5 4}$ & $\mathbf{1 0 . 4 1}$ & $\mathbf{1 3 . 3 9}$ & $\mathbf{8 . 5 0}$ & $\mathbf{0 . 9 8}$ \\
\hline TEXAS & $3.48 \mathrm{a}$ & $22.61 \mathrm{a}$ & $31.54 \mathrm{a}$ & $15.92 \mathrm{a}$ & $2.63 \mathrm{a}$ \\
\hline LSD (\%5) & 0.10 & 0.55 & 1.22 & 0.45 & 0.13 \\
\hline 2014 & $0.70 \mathrm{a}$ & $10.45 \mathrm{a}$ & $16.45 \mathrm{a}$ & $8.64 \mathrm{a}$ & $0.96 \mathrm{a}$ \\
2015 & $0.69 \mathrm{a}$ & $10.30 \mathrm{~b}$ & $16.41 \mathrm{a}$ & $8.60 \mathrm{~b}$ & $0.95 \mathrm{a}$ \\
\hline LSD (\%5) & 0.02 & 0.09 & 0.20 & 0.07 & 0.02
\end{tabular}

Denemede yer alan badem türlerine ait genotiplerin iç badem özellikleri Çizelge 2'de sunulmuştur. Çizelgeden de görüleceği iç badem özellikleri genotiplere göre değişiklik göstermiş, ortalamalar arasındaki farklılıklar istatistiki olarak önemli olmuştur.

İç badem ağırlığı yıllara göre değişiklik göstermemiştir. En yüksek iç badem ağırlığı beklenildiği şekilde kontrol olarak kullanılan Texas çeşidinden $(1.53 \mathrm{~g})$ elde edilmiştir. Denemede yer alan badem türlerine ait genotipler kendi aralarında kıyaslandığında ise $A$. orientalis genotiplerinde en yüksek ortalama iç badem ağırlığı $0.37 \mathrm{~g}$ ile 013 genotipinden elde edilirken, en düşük iç badem ağırlığı $0.15 \mathrm{~g}$ ile $\mathrm{O5}$ genotipinden elde edilmiştir. Öteki $A$. orientalis badem genotiplerinin iç badem ağırlığı ortalamaları verilen değerler arasında dağılım göstermiştir. A. turcomanica genotiplerinde ise en yüksek iç badem ağıllığı $0.32 \mathrm{~g}$ ile $\mathrm{T} 2$ genotipinden elde edilirken, en düşük iç badem ağırlığı $0.15 \mathrm{~g}$ ile T5 genotipinden elde edilmiştir. Öteki $A$. turcomanica genotiplerinin iç badem ağırlığı ortalaması bu değerler arasında yer almıştır. Denemede yer alan badem türlerinde iç badem ağırlığı ortalaması çok yakın olmuştur. Bu değer $A$. orientalis genotipleri için $0.23 \mathrm{~g}, A$. turcomanica genotipleri için $0.21 \mathrm{~g}$ olarak belirlenmiştir. iç badem boyutları da (en, boy, yükseklik) genotiplere göre değişiklik göstermiştir. Gerçekleştirilen ölçümler neticesinde kabuklu bademlerde olduğu şekilde $A$. orientalis genotiplerinde iç bademlerin $(13.54 \mathrm{~mm}) A$. turcomanica genotiplerine $(11.00 \mathrm{~mm})$ kıyasla daha uzun oldukları görülmüştür. $A$. turcomanica genotiplerinde ise iç bademlerin daha geniş $(7.25 \mathrm{~mm})$ oldukları saptanmıştır.
Randıman sert kabuklu meyve türlerinin en önemli kalite kriterlerindendir. Kabuğun ince ve yeterince sağlam, iç ağırı̆̆ının yüksek olması istenilmektedir. Bu özellik doğrudan besin maddesi olarak değerlendirilmeyen yabani badem türleri için geçerli olmamakla birlikte önemli tanımlama kriterlerindendir. Denemede yer alan yabani badem türleri her ne kadar doğrudan tüketilmese de iç doluluğu çimlenme ve çıkış açısından önemli görülmektedir. Bu açıdan yabani badem genotipleri değerlendirildiğinde iç badem randımanlarının genelde yüksek olduğu belirlenmiştir. $A$. orientalis genotiplerinde en düşük iç badem randımanı \%33.69 ile 012 genotipinden elde edilirken, en yüksek değer \%48.11 ile 011 genotipinden elde edilmiştir. $A$. turcomanica genotiplerinde ise iç badem oranı \%33.78 (T2) ile \%42.26 (T6) arasında dağılım göstermiştir. Gerçekleştirilen ölçümler neticesinde $A$. orientalis genotiplerinde iç badem oranı ortalaması (\%39.79) $A$. turcomanica genotiplerinden elde edilen (\%38.78) değerlerle çok yakınlık göstermiştir.

Bayazıt (2007) Gaziantep ve Şanlıurfa illerinden seçtiği $A$. orientalis ve $A$. turcomanica genotiplerinde iç badem ağırlıklarının çok yakın olduğunu (0.19 g - $0.18 \mathrm{~g}$ ) bildirmiştir. Meyve özelliklerinin ekolojilere göre farklıık gösterdiğini bildiren araştırıcı Orta Anadolu'da yetişen $A$. orientalis genotiplerinde iç badem ağırlığı ortalamasının $0.27 \mathrm{~g}$ olduğunu belirtmiştir. Tholkouk ve ark. (2000) Lübnan'da 6 farklı noktadan seçtiği $A$. orientalis genotiplerinde iç badem ağırlıklarının $0.2 \mathrm{~g}$ ile $1.2 \mathrm{~g}$ arasında değiştiğini ortalamasının da $0.4 \mathrm{~g}$ olduğunu belirtmiştir. Chalak ve ark. (2014) Lübnan'da 7 farklı noktadan elde ettikleri $A$. orientalis genotiplerinde iç 
badem ağırlıklarının $0.19 \mathrm{~g}$ ile $0.77 \mathrm{~g}$ arasında değiştiğini bildirmiştir. Sorkheh ve ark. (2009) ise İran'da 5 farklı noktadan seçtikleri $A$. orientalis genotiplerinde iç badem ağırlıklarının $0.3 \mathrm{~g}$ ile $1.2 \mathrm{~g}$ arasında değiştiğini ve ortalamasının da $0.7 \mathrm{~g}$ olduğunu bildirmiştir.

Gerçekleştirilen bu araştırmamızdan elde edilen sonuçlar önceki araştırmaların sonuçları ile genel olarak benzerlik göstermekle birlikte farklılıklarında olduğu görülmektedir. Görülen farklılıkların ekolojik farklılıklar, bitki yaşı, bitkinin bulunduğu toprak koşulları gibi faktörlerden kaynaklanması muhtemeldir. Bununla birlikte görülen farklılıkların temel nedeni araştırma konusu badem türlerine ait genotiplerin tohumdan elde edilmiş olmaları nedeniyle her birinin farklı genetik yapıda olmalarıdır.

Çizelge 2. Badem genotiplerinde iç badem özellikleri Table 2. Kernel properties of almond genotypes

\begin{tabular}{|c|c|c|c|c|c|c|}
\hline Genotip & $\begin{array}{l}\text { Ağırlık } \\
\text { (g) }\end{array}$ & Randıman (\%) & $\begin{array}{c}\text { En } \\
(\mathrm{mm})\end{array}$ & $\begin{array}{l}\text { Boy } \\
\text { (mm) }\end{array}$ & $\begin{array}{l}\text { Yük } \\
\text { (mm) }\end{array}$ & Çift iç oranı (\%) \\
\hline$\overline{01}$ & $0.18 \mathrm{fj}$ & $42.88 \mathrm{ac}$ & $6.02 \mathrm{hl}$ & $11.74 \mathrm{gh}$ & $5.03 \mathrm{df}$ & $0 \mathrm{c}$ \\
\hline $\mathrm{O} 2$ & $0.15 \mathrm{ij}$ & 40.75 bf & $5.19 \mathrm{j}$ & $12.27 \mathrm{~g}$ & $4.87 \mathrm{ef}$ & $\mathrm{Oc}$ \\
\hline $\mathrm{O} 3$ & $0.22 \mathrm{eh}$ & 38.77 bf & $6.10 \mathrm{gl}$ & $14.39 \mathrm{~d}$ & $5.06 \mathrm{cf}$ & $6.14 \mathrm{bc}$ \\
\hline $\mathrm{O} 4$ & $0.25 \mathrm{de}$ & $35.08 \mathrm{df}$ & $6.49 \mathrm{eh}$ & $13.88 \mathrm{de}$ & $5.29 \mathrm{bf}$ & $0 \mathrm{c}$ \\
\hline 05 & $0.15 \mathrm{j}$ & $40.01 \mathrm{bf}$ & 5.67 ij & $11.55 \mathrm{~h}$ & $5.25 \mathrm{bf}$ & $\mathrm{Oc}$ \\
\hline 08 & 0.23 ef & $44.50 \mathrm{ab}$ & $6.04 \mathrm{hl}$ & $13.76 \mathrm{df}$ & $5.29 \mathrm{bf}$ & $0 \mathrm{c}$ \\
\hline 010 & 0.19 ej & 37.88 bf & $6.23 \mathrm{gl}$ & 13.27 ef & $5.01 \mathrm{df}$ & $0 \mathrm{c}$ \\
\hline 011 & $0.24 \mathrm{df}$ & $48.11 \mathrm{a}$ & $6.05 \mathrm{hl}$ & 13.64 ef & $5.90 \mathrm{~b}$ & $\mathrm{Oc}$ \\
\hline 012 & 0.20 ej & $33.69 \mathrm{f}$ & $6.27 \mathrm{fl}$ & 13.34 ef & $5.14 \mathrm{cf}$ & $0 \mathrm{c}$ \\
\hline 013 & $0.37 \mathrm{~b}$ & $37.70 \mathrm{bf}$ & $7.35 \mathrm{~d}$ & $16.19 \mathrm{~b}$ & $5.72 b c$ & $10.57 \mathrm{~b}$ \\
\hline 014 & 0.20 ej & $38.31 \mathrm{bf}$ & 5.98 I & $13.13 \mathrm{f}$ & 5.44 be & $0 \mathrm{c}$ \\
\hline 015 & $0.30 \mathrm{~cd}$ & $37.25 \mathrm{cf}$ & 7.05 de & $15.47 \mathrm{c}$ & $5.38 \mathrm{bf}$ & $6.14 b c$ \\
\hline 016 & 0.23 ef & $42.33 \mathrm{ac}$ & $6.57 \mathrm{eh}$ & 13.27 ef & 5.42 be & $0 \mathrm{c}$ \\
\hline Ortalama & 0.23 & 39.79 & 6.24 & 13.54 & 5.30 & 1.76 \\
\hline$\overline{\mathrm{T} 1}$ & $0.21 \mathrm{ej}$ & $41.36 \mathrm{ad}$ & $6.77 \mathrm{dg}$ & $11.28 \mathrm{~h}$ & $5.56 \mathrm{bd}$ & $0 \mathrm{c}$ \\
\hline $\mathrm{T} 2$ & $0.32 \mathrm{bc}$ & 33.78 ef & $8.83 \mathrm{~b}$ & $13.18 \mathrm{f}$ & $5.35 \mathrm{bf}$ & $0 \mathrm{c}$ \\
\hline T3 & 0.20 ej & 40.84 be & $7.28 d$ & $11.27 \mathrm{~h}$ & $5.15 \mathrm{cf}$ & $\mathrm{Oc}$ \\
\hline T4 & $0.17 \mathrm{gj}$ & 39.06 bf & $6.94 \mathrm{df}$ & $8.66 \mathrm{j}$ & $5.71 b c$ & $3.07 b c$ \\
\hline T5 & 0.15 j j & $37.57 \mathrm{bf}$ & 7.13 de & 9.73 । & $4.72 \mathrm{f}$ & $0 \mathrm{c}$ \\
\hline T6 & $0.21 \mathrm{eh}$ & $42.26 \mathrm{ac}$ & $6.20 \mathrm{gl}$ & $12.24 \mathrm{~g}$ & $5.33 \mathrm{bf}$ & $0 \mathrm{c}$ \\
\hline $\mathrm{T7}$ & 0.16 hj & $36.80 \mathrm{cf}$ & $6.66 \mathrm{dh}$ & 9.921 & $4.88 \mathrm{ef}$ & $0 \mathrm{c}$ \\
\hline $\mathrm{T} 8$ & $0.22 \mathrm{eg}$ & $38.55 \mathrm{bf}$ & $8.12 c$ & $11.69 \mathrm{gh}$ & $5.23 \mathrm{bf}$ & $0 \mathrm{c}$ \\
\hline Ortalama & 0.21 & 38.78 & 7.25 & 11.00 & 5.25 & 0.38 \\
\hline TEXAS & $1.53 \mathrm{a}$ & 43.87 ac & $12.99 \mathrm{a}$ & $22.52 \mathrm{a}$ & $11.14 \mathrm{a}$ & $28.78 a$ \\
\hline LSD (\%5) & 0.06 & 7.10 & 0.70 & 0.68 & 0.67 & 9.02 \\
\hline 2014 & $0.281 \mathrm{a}$ & 40.25 a & $6.97 a$ & $13.06 \mathrm{a}$ & $5.56 \mathrm{a}$ & $2.42 \mathrm{a}$ \\
\hline 2015 & $0.273 a$ & $38.96 \mathrm{~b}$ & $6.84 \mathrm{~b}$ & $12.97 \mathrm{a}$ & $5.52 \mathrm{a}$ & $2.54 \mathrm{a}$ \\
\hline LSD (\%5) & 0.01 & 1.15 & 0.11 & 0.11 & 0.12 & 1.46 \\
\hline
\end{tabular}

A. turcomanica türüne ait genotiplerde iç badem eni, boyu ve yüksekliği değerlerinin $6.11 \mathrm{~mm}$ ile $8.25 \mathrm{~mm}$,
Bayazit (2018) yabani badem türlerinin pomolojik ve kimyasal özelliklerinin saptanması amacıyla gerçekleştirdiği araştırma neticesinde iç badem ölçüm sonuçlarının türlere ve genotiplere göre değiştiğini bildirmiştir. Araştırıcı A. orientalis genotiplerinde iç badem ağırlığının $0.19 \mathrm{~g}$ ile $0.61 \mathrm{~g}$ arasında değiştiğini, iç bademlerde en, boy ve yüksekliklerinin ise sırasıyla 4.79 $\mathrm{mm}$ ile $10.93 \mathrm{~mm} ; 12.09 \mathrm{~mm}$ ile $19.05 \mathrm{~mm}$ ve $4.29 \mathrm{~mm}$ ile $5.86 \mathrm{~mm}$ arasında değiştiğini bildirmiştir. Araştırıcı $A$. turcomanica genotiplerinin tamamında iç badem ağırlığının 0.2 gramın altında olduğunun ve 0.15 g ile 0.19 $\mathrm{g}$ arasında dağılım gösterdiğini bildirmiştir. 
badem oranının \%24.84 ile \%51.37 arasında değişmiştir. Araştırmaların sonuçları arasında farklılıklar bulunmakla birlikte genel itibariyle bir yakınlık söz konusu olmuştur. Denemede yer alan badem genotiplerinde kabuklu ve iç badem indeksleri Çizelge 3'de verilmiştir. Çizelgeden de görüldügü şekilde badem türlerinde meyve şekilleri bariz farklılık göstermiştir. A. orientalis genotiplerinden 01 , 04, 05 ve 014' te meyveler 'geniş' olurken, öteki genotiplerde 'orta' olarak belirlenmiştir. Buna karşılık kontrol olarak kullanılan Texas badem çeşidinde ve $A$. turcomanica türüne ait genotiplerin tamamında kabuklu meyveler 'çok geniş' olarak saptanmıştır. A. turcomanica genotiplerinin tamamında iç bademler 'genişs' ve 'kalın' olarak belirlenmiştir. $A$. orientalis türüne ait genotiplerde ise iç badem genişlik indeksi 'dar' olurken, sadece 01 genotipinde farklılık göstermiş ve öteki genotiplerden ayrılarak 'genişçe' olmuştur. İç badem kalınlık indeksi açısından $A$. orientalis genotipleri değerlendirildiğinde $\mathrm{O} 3,010,013,015$ genotiplerinde iç bademler 'kalınca', öteki genotiplerde ise A. turcomanica genotplerinde olduğu şekilde 'kalın' olarak belirlenmiștir.

Gerek kabuklu badem gerekse iç badem şekilleri genetik yapının kontrolündedir ve çevre koşullarından etkilenmesi olası değildir. Bu nedenle denemede yer alan badem türlerinde net bir farklılık ortaya koyan özellikler olmuştur.

Çizelge 3. Badem genotiplerinde kabuklu ve iç badem şekil indeksleri

Table 3. Nut and kernel shape indexes of almond genotypes

\begin{tabular}{|c|c|c|c|c|c|c|}
\hline \multirow{2}{*}{$\begin{array}{l}\text { Genotip } \\
\mathrm{O} 1\end{array}$} & \multicolumn{2}{|c|}{$\begin{array}{c}\text { Kabuklu badem } \\
\text { indeksi }\end{array}$} & \multicolumn{2}{|c|}{$\begin{array}{c}\text { İç badem } \\
\text { Genişlik Indeksi }\end{array}$} & \multicolumn{2}{|c|}{ İç badem Kalınlık İndeksi } \\
\hline & 59.10 & Geniş & 51.45 & Genişçe & 42.97 & Kalın \\
\hline $\mathrm{O} 2$ & 49.11 & Orta & 42.32 & Dar & 39.73 & Kalın \\
\hline $\mathrm{O} 3$ & 52.33 & Orta & 42.44 & Dar & 35.27 & Kalınca \\
\hline $\mathrm{O} 4$ & 57.24 & Geniş & 46.82 & Dar & 38.25 & Kalın \\
\hline 05 & 59.45 & Geniş & 49.10 & Dar & 45.34 & Kalın \\
\hline 08 & 54.81 & Orta & 44.01 & Dar & 38.56 & Kalın \\
\hline 010 & 54.57 & Orta & 47.00 & Dar & 37.83 & Kalınca \\
\hline 011 & 52.63 & Orta & 44.35 & Dar & 43.30 & Kalın \\
\hline 012 & 53.04 & Orta & 47.00 & Dar & 38.58 & Kalın \\
\hline 013 & 54.39 & Orta & 45.40 & Dar & 35.36 & Kalınca \\
\hline 014 & 57.07 & Geniş & 45.53 & Dar & 41.45 & Kalın \\
\hline 015 & 54.34 & Orta & 45.59 & Dar & 34.81 & Kalınca \\
\hline 016 & 55.13 & Orta & 45.83 & Dar & 38.91 & Kalın \\
\hline Ortalama & 55.13 & Orta & 46.15 & Dar & 39.40 & Kalın \\
\hline$\overline{\mathrm{T} 1}$ & 73.49 & Ç. geniş & 60.07 & Geniş & 49.38 & Kalın \\
\hline $\mathrm{T} 2$ & 79.36 & Ç. geniş & 66.94 & Geniş & 40.68 & Kalın \\
\hline T3 & 74.32 & Ç. geniş & 65.18 & Geniş & 46.14 & Kalın \\
\hline T4 & 96.67 & Ç. geniş & 80.16 & Geniş & 66.02 & Kalın \\
\hline T5 & 85.78 & Ç. geniş & 73.33 & Geniş & 48.54 & Kalın \\
\hline T6 & 60.93 & Ç. geniş & 50.72 & Geniş & 43.60 & Kalın \\
\hline $\mathrm{T7}$ & 82.26 & Ç. geniş & 67.17 & Geniş & 49.24 & Kalın \\
\hline T8 & 77.75 & Ç. geniş & 65.80 & Geniş & 47.76 & Kalın \\
\hline Ortalama & 77.08 & Ç. geniş & 69.02 & Geniş & 45.24 & Kalın \\
\hline TEXAS & 77.09 & Ç. geniş & 57.68 & Geniş & 49.38 & Kalın \\
\hline
\end{tabular}

Ç; çok.

Denemede yer alan badem türlerinden elde edilen morfolojik özelliklere ilişkin sonuçlar Çizelge 4'de verilmiştir. Çalışmada incelenen badem türlerine ait tüm genotiplerde meyve verimi yüksek olarak gözlemlenmiştir. Bu durumun temel nedeni genotiplerin doğal popülasyondan seçim amacının tohum anacı olarak kullanılabilmesi için verimli ve her yıl düzenli meyve veren genotiplerin seçilmesidir.

A. orientalis genotiipleri kültür bademlerine kıyasla daha geç çiçeklenirken, $A$. turcomanica genotiplerinde çiçeklenmenin çok daha geç olduğu belirlenmiştir. Nitekim 2 badem türünün de geç çiçeklenme özelliği 
bilinmekte ve bu özelliklerinin badem ıslahı için önemli olduğu bildirilmektedir (Büyükyılmaz ve Kester, 1976; Denisov, 1988; Gradziel ve ark., 2001).

Yabani badem türleri çalı formunda bitkiler oluşturmaktadır. Bu nedenle gövde sayısı kültür badem çeşitlerine kıyasla çok fazladır. Gerçekleştirilen bu denemede de $A$. orientalis genotiplerinde gövde sayısı 2 ile 8 arasında değişirken, bu sayı A. turcomanica genotiplerinde çok daha yüksek olmuş ve 8 ile 13 arasında değişmiştir. Yabani badem türlerinde taç gelişiminin kültür bademlerine kıyasla çok düşük olduğu ve bodur özellik gösterdiği bilinmektedir (Bayazıt, 2007). Gerçekleştirilen bu araştırmada da kullanılan her badem türüne ait tüm genotiplerin bodur özellikte olduğu gözlemlenmiştir. Ayrıca $A$. turcomanica badem türüne ait genotiplerde taç iriliğinin $A$. orientalis'e kıyasla daha düşük olduğu görülmüştür. İki türe ait tüm badem genotiplerinin 'dikenli' olduğu gözlemlenirken, A.turcomanica badem türüne ait genotiplerin daha 'sık dikenli' olduğu da dikkat çekmiştir.

Denemede kullanılan badem türlerinin kültür badem çeşitleriyle uyumada bir problemlerinin olmaması nedeniyle çöğür anacı olarak kullanılabileceği gibi, anaç ıslahı çalışmalarında da kullanılabileceği bilinmektedir (Browicz and Zohary, 1996; Denisov, 1988;Martinez-
Gómez ve ark., 2005). Özellikle bu türlerin kurak ve olumsuz toprak koşullarına dayanıklı olmaları ve birim alana fazla sayıda bitki dikme avantajına neden olan bodur taç yapısında olmaları tercih edilmelerinin ve araştırma konusu olmalarının en önemli nedenleridir. Bu nedenle bu türlerin morfolojik olarakta tanımlanmaları ıslah çalışmalarında kullanılacak ebeveyn bitkilerin belirlenmesi açısından önemlidir. Ayrıca özellikle $A$. orientalis badem türünün badem için doğrudan anaç olarak kullanılması mümkündür (Atlı, 2008; Bayazıt, 2018). Özellikle tohum anacı olarak kullanılacak bitkilerin her yıl düzenli meyve vermesi ve verimli olması gerekmektedir. Bu açıdan üzerinde çalışılan badem genotiplerinin önemli olduğu görülmekte ve genetik kaynak olarak korunması gerekmektedir. Ayrıca tohum anacı olarak değerlendirilecek genotiplerde verimin yüksek olmasının yanında çimlenme ve çıkış oranlarını yüksek, çöğür gelişiminin bir örnek olması arzu edilmektedir (Çelik, 1983). Bu nedenle çimlenme, çıkış, çöğür gelişimi gibi özelliklerinde ivedilikle belirlenmesi gerekmektedir. Dikenlilik genetik yapının kontrolündedir. Anaç olarak kullanılacak genotiplerin aşı yapımını zorlaştırması nedeniyle istenilmemektedir. Bu açıdan dikenlilik badem türlerinin en önemli dezavantajı olarak görülmektedir.

Çizelge 4. Araştırmada kullanılan badem genotiplerinin morfolojik özellikleri

Table 4. Morphological characteristics of almond genotypes

\begin{tabular}{lccccc}
\hline Genotip adı & Meyve verimi & Çiçeklenme durumu & Gövde sayısı & Taç gelişimi & Dikenlilik durumu \\
\hline O 1 & Yüksek & Geç & 4 & Bodur & Dikenli \\
O 2 & Yüksek & Geç & 4 & Bodur & Dikenli \\
O 3 & Yüksek & Geç & 5 & Bodur & Dikenli \\
O 4 & Yüksek & Geç & 5 & Bodur & Dikenli \\
O 5 & Yüksek & Geç & 2 & Bodur & Dikenli \\
O 8 & Yüksek & Geç & 3 & Bodur & Dikenli \\
O 10 & Yüksek & Geç & 4 & Bodur & Dikenli \\
O 11 & Yüksek & Geç & 4 & Bodur & Dikenli \\
O 12 & Yüksek & Geç & 6 & Bodur & Dikenli \\
O 13 & Yüksek & Geç & 7 & Bodur & Dikenli \\
O 14 & Yüksek & Geç & 8 & Bodur & Dikenli \\
O 15 & Yüksek & Geç & 7 & Bodur & Dikenli \\
O 16 & Yüksek & Geç & 8 & Bodur & Dikenli \\
\hline T 1 & Yüksek & Çok geç & 12 & Çok Bodur & Sık dikenli \\
T 2 & Yüksek & Çok geç & 8 & Çok Bodur & Sık dikenli \\
T 3 & Yüksek & Çok geç & 9 & Çok Bodur & Sık dikenli \\
T 4 & Yüksek & Çok geç & 8 & Çok Bodur & Sık dikenli \\
T 5 & Yüksek & Çok geç & 11 & Çok Bodur & Sık dikenli \\
T 6 & Yüksek & Çok geç & 11 & Çok Bodur & Sık dikenli \\
T 7 & Yüksek & Çok geç & 8 & Çok Bodur & Sık dikenli \\
T 8 & Yüksek & Çok geç & 13 & Çok Bodur & Sık dikenli \\
\hline
\end{tabular}


Denemenin iki yılında da yaprak uzunluğu, genişliği ve alanı açısından en yüksek değerler beklenildiği şekilde kontrol olarak kullanılan Texas çeşidinden elde edilmiştir (Çizelge 5). Yabani badem türlerine ait genotiplerden elde edilen yaprak ölçüm sonuçları yıllara göre değişmiş, ortalamaları arasındaki farklılıklar da istatistiki olarak önemli olmuştur. Denemenin 2. yılı ölçüm sonuçlarının yüksekliği dikkat çekmiştir. Bu durum bitkinin yaşı, bulunduğu toprak koşulu, yükselti ve bakı, beslenme ve o yılki yağış miktarı ve yağışın vejetasyon süresi içerinde düşüp düşmemesine bağlı olarak değişebilmektedir. $A$. orientalis genotiplerinde en düşük yaprak uzunluğu, genişliği ve alanı $2.51 \mathrm{~cm}(02,012), 0.67 \mathrm{~cm}(010)$ ve $1.72 \mathrm{~cm}^{2}(01,02)$ olurken, en yüksek değerler $3.35 \mathrm{~cm}$ (015), $1.11 \mathrm{~cm}$ (011) ve $2.54 \mathrm{~cm}^{2}$ (011) olarak belirlenmiştir. $\mathrm{Bu}$ değerler $A$. turcomanica genotiplerinde 2.06 (T6), $0.45 \mathrm{~cm}$ (T7) ve $0.87 \mathrm{~cm}^{2}(\mathrm{~T} 3$, T7) ile $3.60 \mathrm{~cm}$ (T1), $0.98 \mathrm{~cm}$ (T1) ve $2.51 \mathrm{~cm}$ (T1) olarak tespit edilmiştir. $A$. orientalis genotiplerinde yaprak uzunluk ve genişlik ortalamasının $(3.00 \mathrm{~cm}$ ve $0.98 \mathrm{~cm})$, A. turcomanica genotiplerinin $(2.69 \mathrm{~cm}$ ve $0.61 \mathrm{~cm})$ ortalamasından yüksek olmuştur. Alan uzunluk ve genişliğe paralel şekilde gerçekleşmektedir. Bu nedenle A. orientalis genotiplerinde yaprak alanı ortalaması 2.00 $\mathrm{cm}^{2}$ olurken, bu değer $A$. turcomanica genotiplerinde $1.16 \mathrm{~cm}^{2}$ olarak gerçekleşmiştir. $A$. orientalis genotiplerinin tamamında yaprak rengi 'gri' olarak gözlemlenirken, A. turcomanica genotiplerinde 'yeşil' olarak gözlemlenmiştir.

Yabani badem türleri ile ilgili gerçekleştirilen araştırmalarda meyve özellikleri temel alınmıştır. Bu nedenle yaprak özelliklerinin ölçüldüğü araştırma sayısının azlığı dikkat çekmektedir. Oysa Ladizinsky (1998) özellikle yabani badem türlerinin tanımlanmasında ve türler arası farklılıkların ortaya konulmasında morfolojik karakterlerin temel ve geleneksel tanımlama yöntemi olduğunu belirtmektedir. Bu çalışmada da yaprak iriliği, rengi, gövde sayısı gibi morfolojik özellikler badem türlerinin tanımlanmasında kullanılabilecek net ayırt edici özellikler olarak belirlenmiştir.

Talhouk ve ark. (2000), Lübnan'da yapmış oldukları çalışmada $A$. orientalis Mill. türüne ait bitkilerde yaprak genişliğinin $0.4 \mathrm{~cm}-0.7 \mathrm{~cm}$, yaprak uzunluğunun $1.3 \mathrm{~cm}$ $-2.5 \mathrm{~cm}$ arasında değiştiğini belirtmiştir. Bu değerlerin elde etmiş olduğumuz değerlerden düşük olduğu görülmektedir. Bayazıt (2007), Gaziantep ilinden seçtiği A. orientalis badem tiplerinin yaprak eni ortalamaları 2003, 2004 ve 2005 yıllarında sırasıyla $1.10 \mathrm{~cm}, 1.19 \mathrm{~cm}$ ve $1.25 \mathrm{~cm}$ olarak belirtmiştir. A. turcomenica badem tiplerinde ise yaprak genişliği $0.28 \mathrm{~cm}$ ile $0.54 \mathrm{~cm}$ arasında değişmiştir. Baninasab ve Rahemi (2006) İran'dan seçtiği $A$. orientalis genotipleride yaprak uzunluğunu $2.76 \mathrm{~cm}$, yaprak genişliğini $7.88 \mathrm{~mm}$ ve yaprak alanını ise $125 \mathrm{~mm}^{2}$ olarak bildirmişlerdir. Bu değerler elde etmiş olduğumuz değerlerden yüksek bulunmuştur. Farklıı̆ı̆ın temel nedeni üzerinde çalışılan badem genotiplerinin tohumdan çoğalmış olması nedeniyle genetik yapılarının farklı olmasıdır. Ayrıca bitkilerin yaş ve bulundukları ekolojik koşulların farklıı̆̆ı da önemli düzeyde etki edebilmektedir.

Çizelge 5.Yabani badem genotiplerinde yaprak ölçüm sonuçları

Table 5. Leaf properties of almond genotypes

\begin{tabular}{lcccc}
\hline Genotip & $\begin{array}{c}\text { Uzunluk } \\
(\mathrm{cm})\end{array}$ & $\begin{array}{c}\text { Genişlik } \\
(\mathrm{cm})\end{array}$ & $\begin{array}{c}\text { Alan } \\
\left(\mathrm{cm}^{2}\right)\end{array}$ & Renk \\
\hline O1 & $2.76 \mathrm{el}$ & $0.94 \mathrm{ce}$ & $1.72 \mathrm{ef}$ & Gri \\
O2 & $2.51 \mathrm{hk}$ & $0.89 \mathrm{ce}$ & $1.72 \mathrm{ef}$ & Gri \\
O3 & $3.12 \mathrm{ce}$ & $0.96 \mathrm{bd}$ & $2.03 \mathrm{ce}$ & Gri \\
O4 & $2.73 \mathrm{fl}$ & $1.02 \mathrm{bc}$ & $1.85 \mathrm{df}$ & Gri \\
O5 & $2.58 \mathrm{gj}$ & $0.96 \mathrm{bd}$ & $1.83 \mathrm{df}$ & Gri \\
O8 & $3.00 \mathrm{cf}$ & $0.88 \mathrm{ce}$ & $1.85 \mathrm{df}$ & Gri \\
O10 & $2.17 \mathrm{kl}$ & $0.67 \mathrm{fg}$ & $1.08 \mathrm{hg}$ & Gri \\
O11 & $3.13 \mathrm{~cd}$ & $1.11 \mathrm{~b}$ & $2.54 \mathrm{~b}$ & Gri \\
O12 & $2.51 \mathrm{hk}$ & $0.78 \mathrm{ef}$ & $1.54 \mathrm{fg}$ & Gri \\
O13 & $2.91 \mathrm{de}$ & $0.84 \mathrm{de}$ & $1.79 \mathrm{ef}$ & Gri \\
O14 & $3.10 \mathrm{ce}$ & $0.99 \mathrm{bd}$ & $2.26 \mathrm{bd}$ & Gri \\
O15 & $3.35 \mathrm{bc}$ & $1.03 \mathrm{bc}$ & $2.33 \mathrm{bc}$ & Gri \\
O16 & $2.85 \mathrm{dh}$ & $0.94 \mathrm{ce}$ & $1.86 \mathrm{cf}$ & Gri \\
\hline Ortalama & $\mathbf{3 . 0 0}$ & $\mathbf{0 . 9 8}$ & $\mathbf{2 . 0 0}$ & \\
\hline
\end{tabular}


Çizelge 5 (devamı).Yabani badem genotiplerinde yaprak ölçüm sonuçları Table 1 (continued). Leaf properties of almond genotypes

\begin{tabular}{|c|c|c|c|c|}
\hline $\mathrm{T1}$ & $3.60 \mathrm{~b}$ & $0.98 \mathrm{bd}$ & $2.51 \mathrm{~b}$ & Yeşil \\
\hline $\mathrm{T} 2$ & $2.31 \mathrm{jl}$ & $0.61 \mathrm{gh}$ & $0.94 \mathrm{~h}$ & Yeşil \\
\hline T3 & $2.45 \mathrm{lk}$ & $0.53 \mathrm{gl}$ & $0.87 \mathrm{~h}$ & Yeşil \\
\hline T4 & $2.60 \mathrm{gj}$ & $0.47 \mathrm{hl}$ & $0.91 \mathrm{~h}$ & Yeşil \\
\hline T5 & $2.71 \mathrm{fl}$ & $0.59 \mathrm{gl}$ & $1.10 \mathrm{hg}$ & Yeşil \\
\hline T6 & $2.06 I$ & $0.59 \mathrm{gl}$ & $0.86 \mathrm{~h}$ & Yeşil \\
\hline T7 & $2.79 \mathrm{dl}$ & 0.45 I & $0.87 \mathrm{~h}$ & Yeşil \\
\hline $\mathrm{T} 8$ & $3.02 \mathrm{cf}$ & $0.65 \mathrm{fg}$ & $1.20 \mathrm{hg}$ & Yeşil \\
\hline Ortalama & 2.69 & 0.61 & 1.16 & Yeşil \\
\hline TEXAS & $6.10 \mathrm{a}$ & $1.96 \mathrm{a}$ & $7.78 \mathrm{a}$ & Yeşil \\
\hline LSD (\%5) & 0.36 & 0.17 & 0.47 & \\
\hline 2014 & $2.64 \mathrm{~b}$ & $0.72 \mathrm{~b}$ & $1.37 \mathrm{~b}$ & \\
\hline 2015 & $3.21 \mathrm{a}$ & $0.98 \mathrm{a}$ & $2.40 \mathrm{a}$ & \\
\hline LSD (\%5) & 0.07 & 0.03 & 0.08 & \\
\hline
\end{tabular}

Sonuç olarak, son yılarda nüfusun artmasına karşılık toprakların tuzlulaşması ve kuraklaşması, su kaynaklarındaki azalma gibi olumsuzluklar biyotik ve abiyotik stres koşullarına dayanıklı genotiplerin kullanılmasını gerektirmektedir. Islahta ve üretimde kullanılacak bu materyalin özelliklerinin önceden bilinmesi gerekmektedir. Bu amaçla gerçekleştirilen bu araştırma neticesinde $A$. orientalis ve $A$. turcomanica badem türlerine ait meyve ve morfolojik özellikler tanımlanmıştır. Üzerinde çalışılan genotiplerde meyve veriminin yüksek olması, geç çiçeklenmeleri ve bodur gelişimleri nedeniyle anaç olarak değerlendirilebileceği söylenebilir. Bu nedenle ilk olarak denemede yer alan badem türlerine ait genotiplerde tohumlarda çimlenme, çıkıs, çögür gelişimi, aşı tutma ve fidan gelişiminin belirlenmesi gerekmektedir.

\section{ÖZET}

Amaç: Çalışmada, Gaziantep ilinden seçilen Amygdalus orientalis (Mill) türüne ait 13 ve Amygdalus turcomanica (Lincz) türüne ait 8 genotipin pomolojik ve morfolojik özellikleri belirlenmeye çalışıımıştır.

Yöntem ve Bulgular: Araştırma kapsamında kabuklu meyve ağırlığı (g), kabuklu meyve boyutları (en, boy, yükseklik) (mm), kabuk kalınlığı $(\mathrm{mm})$, iç badem ağırlığı $(\mathrm{g})$, çift iç oranı (\%), iç badem boyutları (en, boy, yükseklik) $(\mathrm{mm})$ ve iç badem oranı (\%) belirlenmiştir. Morfolojik özelliklerden gövde sayısı (adet), dikenlilik durumu (dikenli, az dikenli, değil), taç gelişimi (bodur, çok bodur), yaprak rengi, yaprak uzunluğu ve genişliği $(\mathrm{mm})$ ve yaprak alanı $\left(\mathrm{cm}^{2}\right)$ ölçülmüştür. Amygdalus orientalis (Mill) genotiplerinde kabuklu meyve ağırlığı
$0.38 \mathrm{~g}$ ile $0.99 \mathrm{~g}$ arasında değişirken, Amygdalus turcomanica (Lincz) genotiplerinde $0.41 \mathrm{~g}$ ile $0.95 \mathrm{~g}$ arasında değişmiştir. Meyveler Amygdalus orientalis (Mill) genotiplerinde daha uzunken, Amygdalus turcomanica (Lincz) genotiplerinde daha geniş ve kalın olarak belirlenmiş ve bu türde kabuk kalınlığı da daha yüksek bulunmuştur. i̇ç badem özellikleri kabuklu badem özelliklerine paralel gerçekleşmiştir. Amygdalus turcomanica (Lincz) genotiplerinde gövde sayısının fazla, sık taçlı, daha dikenli, yaprakların yeşil ve boyutlarının ise Amygdalus orientalis (Mill) genotiplerine kıyasla daha küçük olduğu belirlenmiştir. Her iki badem türünün gerek meyve gerekse morfolojik özelliklere ilişkin ölçüm sonuçları kontrol olarak kullanılan Texas badem çeşidinden çok düşük gerçekleşmiştir.

Genel Yorum: Amygdalus orientalis (Mill) genotiplerinin taç yapısının daha iri, gövde sayısını az, yapraklarının gri renkte olduğu belirlenmiştir. İki badem türünde de taç iriliği, gövde sayısı ve yaprak renklerinin yanında meyve özelliklerinin de belirgin şekilde farklı olması nedeniyle tür tanımlanmasında kullanılabileceği belirlenmiştir. Badem türlerinin taç yapıları dikkate alındığında bodur anaç olarak değerlendirilebileceği, badem başta olmak üzere öteki sert çekirdekli meyve türleri ile ilgili uyuşma ve anaçlık performansının saptanması gerektiği sonucu ortaya çıkmıştır.

Çalışmanın Önemi ve Etkisi: Yabani badem türleri olumsuz iklim ve toprak koşullarına dayanım ve Prunus türleri içi bodur anaç olarak kullanılabilme imkanı nedeniyle önemli genetik kaynaklardandır. Genetik kaynakların ıslah ve üretimde kullanılabilmesi için ise tüm özelliklerinin belirlenmesi gerekmektedir. Bu amaçla gerçekleştirilen araştırmada ülkemiz florasında 
doğal olarak yetişen iki badem türünün pomolojik ve morfolojik özelliklerinin saptanması ıslah ve yetiştiricilik çalışmalarında temel niteliğindedir.

Anahtar Kelimeler: Yabani badem, Amygdalus orientalis, Amygdalus turcomanica, morfoloji, pomoloji.

\section{TEŞEKKÜR}

Bu çalışmaya 8943 kod numarasıyla destek veren HMKÜ Bilimsel Araştırma Projeleri Koordinatörlüğüne çok teşekkür ediyoruz.

\section{ÇIKAR ÇATIŞMA BEYANI}

Makale yazarları aralarında herhangi bir çıkar çatışması olmadığını beyan ederler.

\section{ARAŞTIRMACILARIN KATKI ORANI BEYANI}

Yazarlar çalışmaya eşit oranda katkı sağlamış olduklarını beyan eder.

\section{KAYNAKLAR}

Ağaoğlu YS, Çelik H, Çelik M, Fidan Y, Gülşen Y, Günay A, Halloran N, Köksal I, Yanmaz R (1995) Genel Bahçe Bitkileri. A.Ü. Ziraat Fakültesi Eğitim, Araştırma ve Geliştirme Vakfı Yayınları, No 4: $369 \mathrm{~s}$.

Ak BE, Acar I, Sakar E (1998) An investigation on the determination of pomological and morphological trait of wild almond at Şanlıurfa province. Proceedings of The XI GREMPA Seminar, Cahiers Options Mediterraneennes, 56, 139-144.

Atlı HS (2008) Amygdalus orientalis Mill. badem türünün farklı tiplerinin anaçlık özelliklerinin saptanması. T.C. Tarım ve Köy İşleri Bakanlığı, Tarımsal Araştırmalar Genel Müdürlüğü. Yayın No:37. 14 s.

Baninasab B, Rahemi M (2006). Evaluation of three wild species of almond on the basis of their morphological characters. J. Central Eur. Agric. 7: 619-626.

Bayazıt S (2007) Türkiye'nin farklı ekolojilerindeki yabani badem genotiplerinde fenolojik, morfolojik ve pomolojik özellikler ile moleküler yapıların tanımlanması. Çukurova Üniversitesi Fen Bilimleri Enstitüsü, Doktora Tezi, Adana.

Bayazit S (2018) Fruit characteristics and fatty acids content of Amygdalus orientalis (Mill) and Amygdalus turcomanica (Lincz) almond species. Fresenius Environmental Bulletin 27(9): 6021-6030.

Browicz K, Zielinski J (1984) Chology of trees and shrubs in South- West Asia and Adjacent regions. Polish Scientific Publishers, Vol.8. Warzsawa-Poznan $80 \mathrm{~s}$.
Browicz K, Zohary D (1996) The genus Amygdalus L. (Rosaceae) species relationships, distribution and evolution under domestication. Genetic Resources and Crop Evaluation 43: 229-247.

Çelik M (1983). Meyve yetiştiriciliğinde anacın önemi ve Türkiye meyveciliğinde anaç sorunu. A.Ü. Ziraat Fak. Yay. No : 886, $38 \mathrm{~s}$.

Chalak L, Elbitar A, Chehade A (2014) Diversity of wild Prunus in the Bekaa province, Lebanon. Proc. Ist IS on Fruit Culture and Its Traditional Knowledge along Silk Road Countries. Acta Hort. 1032.

Demir I (1990) Genel Bitki Islahı. E. Ü. Ziraat Fakültesi Yayınları No 496: 366 s. E.Ü.Z. F.Ofset Atölyesi IZMIR.

Denisov VP (1988) Almond genetic resources in the USSR and their use in production and breeding. Acta. Hort. 244: 2999-306.

Martínez-Gómez P, Sánchez-Pérez R, Rubio M, Dicenta F, Gradziel TM, Sozzi, GO (2005) Application of recent biotechnologies to prunus tree crop genetic improvement. Cien. Inv. Agr. 32(2). 73-96.

Kester DE, Asay R (1975) Almonds. Advances in fruit breeding. (Ed.J Janick,J.N. Moore). Purdue Univ. Pres; Westlafeyette, Indiana, p.387-418.

Kester DE, Gradziel TM, Grassely C (1991) Almonds (Prunus). Genetic resources of temperate fruits and nut crops. Int. Soc. Hort. Sci. 701-758.

Ladizinsky, G (1998). On teje origine of almond. Genetic Resources and Crop Evolution 46: 143-167.

Özbek S (1978) Özel Meyvecilik. Ç.Ü.Z.F.Yayınları128. Ders Kitabı:11,A.Ü. Basımevi, Ankara, 487s.

Sas (2005) SAS online doc, version 9.1.3. SAS Inst., Cary, NC, USA.

Shalaby M.N., Ghazal AA., El-Rayes R. Aswad, NG (1997) Preliminary ecological and geobotanical Investigations on wild species of almond (Amygdalus L.) in Syria. IPGRI.

Sorkheh K, Shiran B, Rouh V, Asadi E, Jahanbazi H, Moradi H, Gradziel TM, Martinez-Gome, P (2009) Phenotypic diversity within native Iranian almond (Prunus spp.) species and their breeding potential. Genet. Resour. Crop. Evol. 56: 947-961.

Şehirali S, Özgen M, Karagöz A, Sürek M, Adak A, Güvenç i, Tan A, Burak M, Kaymak Ç (2005) Bitki genetik kaynaklarının korunma ve kullanımı. Türkiye Ziraat Mühendisliği VI. Teknik Kongresi.

Talhouk SN, Lubani RT, Baalbaki R, Zurayk R, Alkhatibi A, Parmaksizian L (2000) Phenotypic diversity and morphological characterization of Amygdalus L. species in Lebanon. Genetic Resources and Crop Evolution 47: 93-104. 